\title{
Linking ATR-FTIR and Raman Features to Phenolic Extractability and Other Attributes in Grape Skin
}

\author{
Hugh Byrne \\ Technological University Dublin, hugh.byrne@tudublin.ie \\ Abigain Rooney \\ Technological University Dublin \\ Julio Nogales-Bueno \\ Universidad de Sevilla
}

See next page for additional authors

Follow this and additional works at: https://arrow.tudublin.ie/biophonart

Part of the Medicine and Health Sciences Commons, and the Physics Commons

\section{Recommended Citation}

Byrne, H.J., Nogales-Bueno, J. \& Rooney, A. (2017). Linking ATR-FTIR and Raman Features to Phenolic Extractability and Other Attributes in Grape Skin. Talanta vol. 167, 15 May 2017, pp. 44-50. doi:10.1016/ j.talanta.2017.02.008

This Article is brought to you for free and open access by the DIT Biophotonics and Imaging at ARROW@TU Dublin. It has been accepted for inclusion in Articles by an authorized administrator of ARROW@TU Dublin. For more information, please contact arrow.admin@tudublin.ie, aisling.coyne@tudublin.ie,gerard.connolly@tudublin.ie.

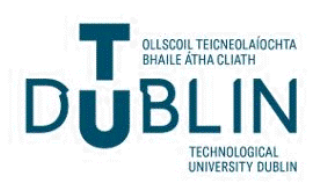




\section{Authors}

Hugh Byrne, Abigain Rooney, Julio Nogales-Bueno, Jose Miguel Hernandez-Hierro, and Francisco Jose Heredia 


\section{Linking ATR-FTIR and Raman features to phenolic extractability and other attributes in grape skin.}

Julio Nogales-Bueno ${ }^{\mathrm{a}}$; Berta Baca-Bocanegra ${ }^{\mathrm{a}}$, Abigail Rooney ${ }^{\mathrm{b}}$, José Miguel Hernández-Hierro ${ }^{\mathrm{a}}$, Francisco José Heredia ${ }^{\mathrm{a}}$ and Hugh J. Byrne ${ }^{\mathrm{b}^{*}}$.

${ }^{a}$ Food Colour and Quality Laboratory, Department of Nutrition and Food Science, Facultad de Farmacia, Universidad de Sevilla, 41012 Sevilla, Spain.

${ }^{\mathrm{b}}$ FOCAS Research Institute, Dublin Institute of Technology, Kevin Street, Dublin 8, Ireland

* Corresponding author: Hugh J. Byrne

Phone: +353 14027900

Fax: +35314027904

E-mail: Hugh.Byrne@dit.ie 


\begin{abstract}
The importance of wine phenolics on the sensory characteristic of red wines is wellknown. Therefore, it is necessary to control the extractability of phenolic compounds from grape skins, which depends significantly on grape ripeness and hence, on cell wall degradation.

In the present study, attenuated total reflectance Fourier transform infrared (ATR-FTIR) and Raman spectra of grape skin have been recorded. Then, these spectral matrices have been studied and the main spectral features have been linked to extractabilities of phenolic compounds (anthocyanins, flavanols and total phenols). Moreover, spectral differences between external and internal grape skin surfaces also have been studied.

It has been confirmed that the amount of polysaccharides and the degree of esterification of pectins have significant influence on the phenolic extractability levels of grape skin tissue.
\end{abstract}

\title{
Keywords
}

Wine, grape skins, phenolic extractability, ATR-FTIR spectroscopy, Raman spectroscopy, hyperspectral imaging. 


\section{Introduction}

Phenolic compounds are characterised by having at least one aromatic ring with one or more hydroxyl groups attached. Phenolics can be flavonoids or non-flavonoids, flavonoids being the most numerous in the plant kingdom. Flavonoids are polyphenolic compounds comprising fifteen carbons, with two aromatic rings connected by a threecarbon bridge. They are found in high concentrations throughout the plant kingdom in the epidermis of leaves and the skin of fruits. They have important and varied roles as secondary metabolites [1]. Flavonoids have well-known health benefits. They possess ideal structural chemistry for free radical-scavenging activities, and they have been shown to be more effective antioxidants in vitro than vitamins $\mathrm{E}$ and $\mathrm{C}$ on a molar basis $[2]$.

The majority of flavonoids in red grapes (Vitis vinifera L.) are found in the seeds and berry skins and are transferred to the wine during the fermentation process. The main subclasses of flavonoids present in red grapes are flavonols, flavanols and anthocyanins. Flavonols and anthocyanins are principally localized in the skins, whereas flavanols are synthesized primarily in seeds and stems [3]. Anthocyanins are red-coloured phenols that give to red wine its characteristic colour [4]. Flavanols can increase and stabilize the wine colour by means of the copigmentation phenomenon $[5,6]$.

Wine phenolics content depends mainly on the amount of phenolic compounds released from grape to wine. In consequence, it is really important to control the amount of phenolic compounds that may be extracted from grapes to wine. It is well known that extractability of anthocyanins and phenolic acids from grapes depends significantly on grape ripeness. Riper grapes have higher cell wall degradation, and hence they have higher extraction degree [7-9]. 
Several methodologies have been developed in order to control and understand the relationship between cell wall composition and the extraction degree of phenolic compounds. An increase in the sugar content (degree of ripening) has been correlated with decreasing amounts of cell wall material, galactose, cellulose and mannose, accompanied by a decrease in the degree of methylation of pectic polysaccharides or pectins. These factors could be responsible for the different phenolic compounds extractability, bearing in mind that differences in thickness or density of the skin cellwall could also play a role [10].

Another important factor to take into account in grape skin extractability is the existence of differences in cell wall composition between grape skin surfaces. The grape skin consists of three anatomically distinguishable regions, the outer cuticle followed by the epidermis and by the inner hypodermis. There are no phenolic compounds in the cuticle, it is composed of hydroxylated fatty acids collectively termed cutin and is covered by hydrophobic waxes. The intermediate epidermis, assumed to consist of one or two layers, appears as a regular tiling of cells, and, finally, the hypodermis is the layer closest to the pulp and is composed of several cell layers that contain most of the phenolics in grape skin $[11,12]$. Therefore, depending on the wine crusher efficiency, phenolic compounds extractability can change within the same grape mass [13]. It is therefore of interest to know how cell wall structure changes within these regions and how this change affects phenolic compounds extractability.

Near infrared spectroscopy (NIRS) has been used in order to screen total or extractable phenolic compounds in grapes obtaining quite good results [14-19]. However, despite the fact that features in the near infrared region can be used to relate skin cell wall composition to phenolic compounds extractability, it is not possible to interpret this relationship in detail. The near infrared (NIR) region contains absorption bands 
corresponding to overtones and combinations of fundamental $\mathrm{C}-\mathrm{H}, \mathrm{O}-\mathrm{H}$ and $\mathrm{N}-\mathrm{H}$ vibrations. Additionally, the presence of Fermi resonances can also increase the complexity of the NIR spectra. Therefore, many band assignments can only be tentative or unresolved which limits the usefulness of the near infrared region in structural determination. By comparison, mid infrared spectra exhibit sharp and narrow peaks essentially related to fundamental modes of vibration which can be easily assigned to chemical structures [20]. Mid infrared spectroscopy has been used in order to relate skin cell wall composition to anthocyanin extractability [7, 21]. In these studies, mid infrared spectral features could be directly linked to the esterification of pectins, which might be responsible for the different extractabilities of the aforementioned phenolic compounds. With the exception of this study, to the best of our knowledge mid infrared spectroscopy has not been used to study the relationship between cell wall composition and phenolic compounds extractability in grapes.

The cell wall structure of grapes and other fruits has been widely studied by means of vibrational spectroscopy. Vibrational spectroscopy is a subset of spectroscopy which comprises infrared (IR) and Raman spectroscopy and analyses vibrations within a molecule (or material) [22]. These two vibrational spectroscopic techniques are, in fact, very complementary. Whereas electric dipole transitions of IR (and UV-visible) absorption require a change of the dipole moment of the material as a result of the transition, Raman scattering requires a change in the polarizability of the bond as a result of the transition. Thus, access to molecular level information can be achieved by means of two different physical processes [23].

Mid infrared spectroscopy has been employed to study cell wall structure of grapes and other fruits [24-27]. Raman spectroscopy has also been employed with the same aim [28-31]. Therefore, both mid infrared and Raman spectroscopy have proved to be useful 
and reliable techniques in the study of cell wall structures of plant and fruit tissues. However, no study which applies Raman spectroscopy to grape samples has been found.

In the present study, Raman and attenuated total reflectance Fourier transform infrared (ATR-FTIR) spectra have been collected for grape skin samples. Two varieties and different phenolic compounds extractabilities have been taken into account. Total phenol, flavanol and anthocyanins extractabilities were obtained for these samples. The main aim of this study is to analyse ATR-FTIR and Raman spectra in order to relate their more important features to phenolic extractability levels in grape skin. Moreover, spectral features are also related to the principal sample attributes. To our knowledge, this is the first time that the aforementioned aims have been jointly addressed.

\section{Material and methods}

\subsection{Samples}

V. vinifera L. cv. Syrah and Tempranillo red grape samples were collected from two vineyards located in the Condado de Huelva Designation of Origin D.O. (Andalusia, Spain). Grapes were collected on two different dates, when Tempranillo and Syrah vineyards were respectively harvested (Tempranillo grapes on $12^{\text {nd }}$ of August and Syrah grapes on $27^{\text {th }}$ of August, 2013). A total of two hundred Syrah and Tempranillo grapes were collected, one hundred per variety. In order to achieve representative sample sets, grapes were collected from the top, middle and bottom of the cluster and from the sunlight and shade side. One grape was collected for each vine and 4 rows were collected in each vineyard. The samples were immediately refrigerated at $4{ }^{\circ} \mathrm{C}$ and immediately carried to the laboratory. Finally, with the aim of selecting a representative grape skin subset, near infrared hyperspectral analyses were carried out. 


\subsection{Sample selection}

Grape samples were tempered and subjected to the hyperspectral analysis. The individual hyperspectral image of each whole grape was recorded and the near infrared spectrum was saved (between 950 and $1650 \mathrm{~nm}$ ). Then, sample selection was carried out as described by Nogales-Bueno, Baca-Bocanegra, Rodríguez-Pulido, Heredia and Hernández-Hierro [16]. Briefly, an unsupervised pattern recognition technique, principal component analysis (PCA), was used to select representative samples from the spectral data set. Five principal components were taken into account. Ninety per cent of the spectral variability of the original spectral matrix was explained. Mahalanobis distances $(\mathrm{H})$ for each sample were calculated and samples were grouped according to a neighbourhood Mahalanobis distance (or neighbourhood $\mathrm{H}$ ) criterion. A threshold of $\mathrm{NH} \leq 0.6$ is usually applied for grouping samples for similar purposes. In this way, the distribution of samples in the spectral space is optimal for accurate predictions $[16,32$, 33]. Thus, 34 groups with different spectral characteristics were created. Due to the heterogeneous sample distribution in the spectral space, groups had different number of samples, ranging from one to several tens. One sample from every group was selected to be used in the subsequent analysis. Win ISI (v1.50) (Infrasoft International, LLC, Port. Matilda, PA, USA, 2000) software was used for this analysis. Grape skins were separated manually from the whole grapes, weighed immediately frozen and stored at $20^{\circ} \mathrm{C}$ until the subsequent analysis.

\subsection{Model wine and exhaustive extractions}

Two different extractions were carried out: a model wine extraction and an exhaustive extraction. 
For model wine extraction, grape skins were immersed in a model wine hydroalcoholic solution ( $4 \mathrm{~g} \mathrm{~L}^{-1}$ tartaric acid, $12.5 \%$ ethanol, adjusted at $\mathrm{pH} 3.6$ with $\left.\mathrm{NaOH} 0.5 \mathrm{M}\right)$ for a maceration period of $72 \mathrm{~h}$. Then, supernatants were used into the subsequent analyses. Afterwards, grape skin samples were freeze-dried, macerated in methanol containing $0.1 \%$ of $12 \mathrm{M} \mathrm{HCl}$, sonicated during 15 minutes (JP Selecta, Barcelona, Spain) and centrifuged $(830 \times g, 15 \mathrm{~min})$. These extractions were repeated twice in order to achieve an exhaustive extraction of phenolic compounds. The methanolic extracts were combined and finally made up to a final volume of $25 \mathrm{~mL}$ with methanol.

As a result of model wine and exhaustive extractions, non-extracted material (NEM) was obtained from each grape skin sample. These NEM samples were freeze-dried and then stored in a desiccator until further use.

2.4. Total phenol, flavanol and anthocyanin extractability determinations Total phenol, flavanol and anthocyanin extractabilities were determined for grape skin samples. They were determined for each supernatant coming from model wine and exhaustive extractions. Then, extractabilities of each sample were evaluated, respectively, as the fractions of total phenols, flavanols and anthocyanins extracted by the model wine solution with respect to the exhaustive extraction. Finally, grape skin samples were sorted according to their phenolic extractability levels expressed as percentages.

Total phenol contents were determined using the Folin-Ciocalteu method [34]. Two hundred microliters of exhaustive or model wine extractions were mixed with $1.5 \mathrm{~mL}$ of sodium carbonate $(20 \% \mathrm{w} / \mathrm{v}), 500 \mu \mathrm{L}$ of Folin reagent and made up to $10 \mathrm{~mL}$ with ultrapure water. After a two-hour period, the absorbances of these solutions were measured against the blank (prepared in the same way with ultrapure water) at a wavelength of $765 \mathrm{~nm}$ using a cuvette with $1 \mathrm{~cm}$ optical path. Gallic acid was used as a 
standard for construction of the calibration curve and the concentration of total phenols was expressed as gallic acid equivalent in $\mathrm{mg} \mathrm{g}^{-1}$ of grape skin.

Flavanol contents were determined following a modification of Vivas, Glories, Lagune, Saucier and Augustin [35]. Ten or twenty microliters of exhaustive or model wine extractions were mixed with 190 or $180 \mu \mathrm{L}$ of methanol respectively and $1 \mathrm{~mL}$ of DMACA reagent. The DMACA (4-dimethylaminocinnamaldehyde) reagent was prepared immediately before use, containing $0.1 \%(\mathrm{w} / \mathrm{v})$ DMACA in a mixture of $\mathrm{HCl}$ :methanol (1:10, v/v). After a ten-minute period, the absorbance at $640 \mathrm{~nm}$ was measured for each sample. A calibration curve of (+)-catechin was used for quantification.

Both Folin and DMACA analyses were performed on an Agilent 8453 UV-visible spectrophotometer (Palo Alto, USA), equipped with diode array detection (DAD). The extract volumes were appropriately modified for samples which needed it.

Anthocyanin contents were determined by means of chromatographic analysis following a modification of the method of García-Marino, Hernández-Hierro, RivasGonzalo and Escribano-Bailón [36] as described in Hernández-Hierro, Nogales-Bueno, Rodríguez-Pulido and Heredia [37]. Two millilitres of exhaustive grape skin extractions were concentrated under vacuum at $30{ }^{\circ} \mathrm{C}$ (Eppendorf Concentrator Plus, Hamburg, Germany) until methanol was removed and finally made up to $1 \mathrm{~mL}$ with $0.1 \mathrm{HCl} \mathrm{M}$. Exhaustive and model wine extractions were diluted $1: 2$ with $0.1 \mathrm{M} \mathrm{HCl}$, filtered through $0.45 \mu \mathrm{m}$ pore size filters and directly injected into the chromatographic system.

2.5. ATR-FTIR data collection

ATR-FTIR spectra were recorded with the Perkin Elmer (MA, USA) Spotlight 400N Universal Attenuated Total Reflectance (UATR) accessory of the spectrometer, which employs a 9-bounce diamond top-plate for this analysis. Spectral data were the result of 
32 scans, with a spectral resolution of $1 \mathrm{~cm}^{-1}$ and covered the spectral range between 4000 and $600 \mathrm{~cm}^{-1}$ (2500 to $\left.16666 \mathrm{~nm}\right)$.

All samples were measured with a force gauge of 140 units. NEM from grape skin samples were cut in several parts and 3 absorption spectra were collected from the internal and external surfaces of the skin. A background spectrum was also recorded and automatically subtracted by the software. The background spectrum was acquired as described above, although no sample was placed into the UATR accessory.

2.6.Raman data collection

A Horiba Jobin-Yvon LabRAM HR800 spectrometer with an external $300 \mathrm{~mW}$ diode laser operating at $785 \mathrm{~nm}$ as source was used throughout this work. For the measurements, a $\times 100$ immersion objective (LUMPlanF1, Olympus) was employed, providing a spatial resolution of $\sim 1 \mu \mathrm{m}$ at the sample. The confocal hole was set at 100 $\mu \mathrm{m}$, the specified setting for confocal operation. The system was spectrally calibrated to the $520.7 \mathrm{~cm}^{-1}$ spectral line of silicon and the intensity response function was corrected using the Standard Reference Material (SRM) No. 2243 of the National Institute of Standards, Boulder, Colorado, USA (NIST SRM 2243, 2242, 2241). The LabRAM system is a confocal spectrometer that contains two interchangeable gratings (300 and 900 lines per mm respectively). In the following experiments, the 300 lines per $\mathrm{mm}$ grating was used, giving a spectral dispersion of $\sim 1.5 \mathrm{~cm}^{-1}$ per pixel. The detector used was a 16-bit dynamic range Peltier cooled CCD detector.

All spectra were recorded covering the spectral range between 3500 and $400 \mathrm{~cm}^{-1}$ and with a spectral resolution of $\sim 1.6$ to $0.9 \mathrm{~cm}^{-1}$. Three spectra were collected on the internal and external surfaces of the NEM from grape skin samples. Samples were measured under water immersion to minimise the spectral background, and spectra were recorded using the immersion objective. 


\subsection{Data analysis}

K-means cluster analysis was carried out in order to sort grape skin samples according to their phenolic extractability levels (total phenol, flavanol and anthocyanin extractabilities). Initial cluster centres were chosen in order to maximize initial betweencluster distances. Samples were sorted into three groups, low, medium and high phenolic extractability levels. K-means analysis was carried out by means of Statistica v.8.0 software from StatSoft Inc. ${ }^{\circledR}$ (StatSoft Inc., OK, USA, 2007).

Both ATR-FTIR and Raman raw data needed spectral pre-treatments. After testing different spectral pretreatments, such as standard normal variate (SNV), detrend, multiplicative scatter correction (MSC), derivatives, baseline correction and resonant Mie scattering (RMieS) correction, a MSC and a baseline correction showed the best results for the pretreatment of ATR-FTIR and Raman raw data, respectively. MSC was applied to ATR-FTIR data in order to remove the scattering caused mainly by particle size and compaction. Win ISI (v1.50) software was used for this aim. Baseline correction was carried out using MATLAB R2012b (The Mathworks, Natik, MA, USA, 2012) and following the algorithm described elsewhere in Mazet, Carteret, Brie, Idier and Humbert [38]. This algorithm estimates the background of a spectrum by means of a non-quadratic cost function. Afterwards, this cost function was subtracted from the raw spectra. Asymmetric truncated quadratic was the cost function which gives the best results to estimate background on Raman spectra of NEM from grape skin samples. Moreover, the backgrounds were estimated by a 4-order polynomial and with thresholds of 0.01 .

Peak heights were calculated for ATR-FTIR and Raman pre-treated spectra and PCA was applied to both spectral and peak height matrices. PCA is an unsupervised pattern recognition technique which is used to provide information about the latent structure of 
the spectral matrix. When PCA is used for exploratory purposes, it is quite common not to fix the number of components very accurately [39]. Therefore, in this sort of study, it is not usual to apply any method for PCA validation [19, 40, 41]. Win ISI (v1.50) software was used for PCA of spectral matrices, whereas peaks heights and PCA for peak height matrices were calculated by means of Statistica v.8.0 software from StatSoft Inc. ${ }^{\circledR}$ Furthermore, univariate analyses of variance (Tukey post hoc test) were applied to look for differences in the peak heights (dependent variables) among different factors (extractability levels, skin surface sides or grape varieties). The statistically significant level was considered at $\alpha=0.05$. Statistica v.8.0 software from StatSoft Inc. ${ }^{\circledR}$ was used to develop these analyses.

\section{Results and discussion}

\subsection{Total phenol, flavanol and anthocyanin extractability levels}

K-means cluster analysis sorted grape seed samples in three different groups. The analysis allocated samples into groups according to their total phenols and flavanols extractability levels and, afterwards, these groups were named as low, medium and high extractability levels. Table 1 shows extractability levels of total phenols, flavanols and anthocyanins for grape skin samples and the number of samples classified in each cluster by the k-means method. A univariate analysis of variance was carried out using extractability of total phenols, flavanols and anthocyanins as dependent variables and extractability levels (low, medium or high) as independent variables or factors. As expected, significant differences were found among different extractability levels.

\subsection{ATR-FTIR data}

Fig. 1A shows the average and standard deviation of raw spectra for the external and internal surfaces of NEM from grape skin samples. Large differences can be seen at first sight, coinciding with the maximum and minimum of the spectra. MSC pre-treatment 
was applied to ATR-FTIR spectra and average spectra were calculated for external and internal surfaces of each grape skin NEM sample. Then, the spectra were vector normalised and mean centred. Afterwards, a PCA was applied to this spectral matrix. Overall, the spectral variability explained was $99 \%$ using 6 principal components (as automatically selected by the software Win ISI) and Mahalanobis distances for each sample were calculated. Samples were ranked in order of their $\mathrm{H}$ (Mahalanobis) distance from the mean spectrum of the entire sample set and the $\mathrm{H}>3$ criterion was applied, samples with a Mahalanobis distance $(\mathrm{H})$ higher than 3 were considered as spectral outliers. Three H-outliers were found, among the external surface spectra which did not meet this criterion and they were not taken into account hereafter. Fig. 1B shows the scores of the grape skin NEM samples in the space defined by the first and second principal components which described $93.82 \%$ (PC1) and $2.50 \%$ (PC2) of the variability in the data. In this plot, it is possible to find differences between both grape skin surfaces. Notably, external and internal skin surface spectra are differentiated according to PC1. Moreover, external surface spectra show higher intragroup variability than internal surface spectra, this variability is described by PC2. This is probably due to cuticle loss suffered by the external surface during general weathering. Neither a cultivar (i.e. Tempranillo and Syrah) or extractability level comparison is shown because the samples were overlapped in this plane. The loadings of PC1 and PC2 are shown in Fig. 1C and different features corresponding to biologic tissues, such as waxes, pectins, monosaccharides, polysaccharides and lipids can be identified (see Table 2) [26, 42-44].

Fig. 1D compares the loading of PC1 (Fig. 1C) with the average spectra of external and internal surfaces of NEM from grape skin samples. In this case, MSC pre-treated spectra are shown. The primary observation is that, when peaks in the spectrum of the external 
surface are stronger than peaks in internal surface spectrum, positive features appear in PC1 and vice versa. In fact, if the plot of the loadings of PC1 is compared with the difference between the external surface average spectrum minus the internal surface average spectrum, both lines overlap almost exactly (Fig. 1D). Therefore, PC1, which describes $93.82 \%$ of the spectral variability and contributes substantially to the differentiation of the internal and external surface spectra in the score plot of Fig. 1B, can be understood as the difference between external and internal spectra of NEM from grape skin samples as previously stated in Bonnier and Byrne [40].

Consequently, the main features that appear in PC1 plot (at 720, 1118, 1167, 1464, 1612, 1732, 2850, 2916 and $3324 \mathrm{~cm}^{-1}$ in Fig. 1C) are responsible for the differences between the two grape skin surfaces. The abroad band at $3324 \mathrm{~cm}^{-1}$ is assigned to the stretching vibration of hydroxyl groups that interact by hydrogen bonding. The intensity of this band depends on the polysaccharide fraction and, secondly, the non-esterified hydroxyl groups of cutin [44]. This band is negative in the PC1 plot, thus the polysaccharide fraction must be lower in the external grape skin surface than in the internal. This fact is confirmed by the spectral shape of the quite broad peak at 1018 $\mathrm{cm}^{-1}$. In this region, the absorptions of the $\mathrm{C}-\mathrm{O}$ stretching mode of polysaccharides (cellulose, hemicellulose or pectins) appear [45]. The PC1 plot shows a minimum in this region, which indicates a significant amount of polysaccharides into the internal grape skin tissue. Bands at 720, 1464, 2850 and $2916 \mathrm{~cm}^{-1}$ are due to $\mathrm{CH}_{2}$ rocking, scissoring and symmetrical and asymmetrical stretching, respectively. These bands were ascribed to the aliphatic material present in the plant cuticle: cutin, waxes and cutan [44]. They are all positive peaks in the PC1 plot, which is consistent with the fact that the cuticle is only on the external surface of the skin. Next, peaks at 1732 (stretching of the carboxylic group) and $1612 \mathrm{~cm}^{-1}$ (stretching of the $\mathrm{C}=\mathrm{O}$ bond of the ester carbonyl 
group) are ascribed to esterified and non-esterified pectins respectively. The degree of esterification of pectins has influence on cell wall porosity and strength [46]. The high intensity of the band around $1732 \mathrm{~cm}^{-1}$ and the low intensity of the band around 1612 $\mathrm{cm}^{-1}$ indicates a high degree of esterification of pectins and vice versa. In addition, changes in spectral shape and peak shifts (particularly the peak at $1612 \mathrm{~cm}^{-1}$ ) to higher wave numbers also indicate a high degree of esterification of pectins [27, 43]. The PC1 plot shows a positive peak at $1732 \mathrm{~cm}^{-1}$ and a negative one at $1612 \mathrm{~cm}^{-1}$. Moreover the peak ascribed to stretching of the $\mathrm{C}=\mathrm{O}$ bond of the ester carbonyl group is shifted from $1612 \mathrm{~cm}^{-1}$ in the internal grape skin to $1620 \mathrm{~cm}^{-1}$ in the external grape skin (Table 2). Therefore, the degree of esterification of pectins is higher in external grape skin than in internal grape skin. The peak at $1167 \mathrm{~cm}^{-1}$, which only appears in external grape skin spectra, is ascribed to asymmetrical $\mathrm{C}-\mathrm{O}-\mathrm{C}$ ester stretching vibrations, and is associated with the cutin matrix [44].

In addition, with the aim of looking for spectral differences related to extractability differences, peak heights were measured in MSC pre-treated spectra. Ten and eight peaks were taken into account for external and internal surfaces of NEM from grape skin samples, respectively (Table 2). A univariate analysis of variance was carried out using peak heights as dependent variables and extractability levels (low, medium or high) as independent variables or factors. No significant differences were found among external surface peaks. However, significant differences $(\mathrm{p}<0.05)$ were found for three internal surface peaks $\left(3324,1732\right.$ and $1018 \mathrm{~cm}^{-1}$ ) among samples with low extractability levels and samples with medium or high extractability levels. As explained earlier, these peaks are assigned to bonds present in polysaccharides and the peak at $1732 \mathrm{~cm}^{-1}$ is also closely linked to the degree of esterification of pectins $[26,27$, 42-45, 47]. Therefore, the results reaffirm that the amount of polysaccharides and the 
degree of esterification of pectins have significant influence on the phenolic extractability levels of grape skin tissue. However, this evidence has only been found in the internal surface of grape skin, probably due to the absence of phenolic compounds in the external cuticle.

\subsection{Raman data}

In order to confirm and consolidate the above findings, Raman spectra were measured for NEM from grape skins. Eight samples were randomly selected (taking care to select from different varieties or extractability levels) and Raman spectra were acquired under water immersion, using the immersion objective to minimise the spectral background [48]. Three spectra were collected on the internal and external surfaces of the grape skin NEM samples and quite noisy spectra with several peaks were obtained. However, after baseline correction, peak heights could be measured for 6 peaks at 1123, 1295, 1342, 1442, 1606 and $2902 \mathrm{~cm}^{-1}$ shift. These peaks were selected because they had a good signal to noise ratio and were present in most samples. Differences between skin surfaces are not obvious at first sight (data not shown). A tentative assignment is shown in Table 3 [28, 30, 31, 49-51].

Fig. 2A shows a typical raw grape skin NEM spectrum and the baseline correction procedure. After baseline correction, a PCA analysis was applied to Raman spectral data and no trends were found (data not shown). Afterwards, using peak heights as variables, a new PCA was carried out. More than $95 \%$ of the data variability is described by the first 3 principal components and PC1 and PC2 describe 58.54\% and $33.71 \%$ respectively. In this case, a PC1-PC2 combination allows a grape skin surface separation (Fig. 2B).

Moreover, one-way univariate analyses of variance were performed. Peak heights were used as dependent variable whereas grape skin surface, grape variety and extractability 
levels (low, medium or high) were used as independent variables or factors in the different analyses. Significant differences $(\mathrm{p}<0.05)$ were found for peaks at 1342 and $1606 \mathrm{~cm}^{-1}$ among Tempranillo and Syrah samples and for peaks at 1295, 1442 and 2902 $\mathrm{cm}^{-1}$ among internal and external surfaces of the grape skin NEM samples. In addition, significant differences were found, only in internal surface spectra, for peaks at 1123 , 1342 and $1606 \mathrm{~cm}^{-1}$ among low extractability level and medium and high extractability levels.

Bands at 1295,1442 and $2902 \mathrm{~cm}^{-1}$ can be assigned to $\mathrm{CH}_{2}$ twisting, scissoring and stretching respectively [49]. Taking into account the fact that there are significant differences in these bands among the different grape skin surfaces, they could be mainly ascribed to the aliphatic material presents in the plant cuticle. The band at $1123 \mathrm{~cm}^{-1}$ is due to symmetric stretching of glycosidic $\mathrm{C}-\mathrm{O}-\mathrm{C}$ bonds in cellulose and other polysaccharides [31]. The band at $1342 \mathrm{~cm}^{-1}$ is due to $\mathrm{HCC}, \mathrm{HCO}, \mathrm{HOC}$ bending in cellulose [50] and finally, the band at $1606 \mathrm{~cm}^{-1}$ is due to stretching of aromatic rings of the remaining phenolic compounds [51]. In consequence, these results show and confirm that phenolic extractability is influenced by polysaccharides and that the remaining phenolic compounds can be detected by Raman spectroscopy, mainly in the internal grape skin surface.

\section{Conclusions}

ATR-FTIR and Raman spectroscopy have been proven to be an effective and reliable tool to relate the more important spectral features to phenolic extractability levels in grape skin samples. ATR-FTIR results reaffirm that the amount of polysaccharides and the degree of esterification of pectins have significant influence on the phenolic extractability levels of grape skin tissue. However, this evidence has only been found in the internal surface of grape skin, probably due to the absence of phenolic compounds 
in the external cuticle. Moreover, these results are supported by Raman data, which show significant differences among phenolic extractability levels in peaks linked to polysaccharides and to the degree of esterification of pectins (internal surface mainly). Moreover, large spectral differences have been found between external and internal grape skin surfaces. These differences are probably due to the different grape skin layers and their different physical and chemical properties.

\section{Abbreviations Used}

ATR-FTIR, attenuated total reflectance Fourier transform infrared; DAD, diode array detector; DMACA, 4-dimethylaminocinnamaldehyde; IR, infrared; H, Mahalanobis distance; MSC, multiplicative scatter correction; NEM, non-extracted material; NH, neighborhood Mahalanobis distance; NIR, near infrared; NIRS, near infrared spectroscopy; PC, principal component; PCA, principal component analysis.

\section{Acknowledgements}

The authors thank the technical staff of Biology Service [Servicios Generales de Investigación (SGI), Universidad de Sevilla].

\section{Funding}

This work was supported by the Spanish MINECO [grant numbers BES-2012-060192, EEBB-I-15-09193 and project AGL2014-58486-C2]; Universidad de Sevilla [VPPI].

\section{References}

[1] A. Crozier, M.N. Clifford, H. Ashihara, Plant Secondary Metabolites. Occurrence, Structure and Role in the Human Diet, Blackwell Publishing, Oxford, England, 2006.

[2] C.A. Rice-Evans, J. Miller, G. Paganga, Antioxidant properties of phenolic compounds, Trends Plant Sci. 2(4) (1997) 152-159. 
[3] R.S. Jackson, Chemical Constituents of Grapes and Wine, in: R.S. Jackson (Ed.), Wine science: principles, prectice and perception, Academic Press, San Diego, California, 2000, pp. 232-280.

[4] A.L. Waterhouse, Wine phenolics, The New York Academy of Sciences, New York, New york, 2002.

[5] B. Gordillo, F.J. Rodríguez-Pulido, M.L. González-Miret, N. Quijada-Morín, J.C. Rivas-Gonzalo, I. García-Estévez, F.J. Heredia, M.T. Escribano-Bailón, Application of Differential Colorimetry To Evaluate Anthocyanin-Flavonol-Flavanol Ternary Copigmentation Interactions in Model Solutions, J. Agric. Food. Chem. 63(35) (2015) 7645-7653.

[6] J. Nogales-Bueno, B. Baca-Bocanegra, M.J. Jara-Palacios, J.M. Hernández-Hierro, F.J. Heredia, Evaluation of the influence of white grape seed extracts as copigment sources on the anthocyanin extraction from grape skins previously classified by near infrared hyperspectral tools, Food Chem. 221 (2017) 1685-1690.

[7] J.M. Hernández-Hierro, N. Quijada-Morín, L. Martínez-Lapuente, Z. Guadalupe, B. Ayestarán, J.C. Rivas-Gonzalo, M.T. Escribano-Bailón, Relationship between skin cell wall composition and anthocyanin extractability of Vitis vinifera L. cv. Tempranillo at different grape ripeness degree, Food Chem. 146(0) (2014) 41-47.

[8] P. Ribéreau-Gayon, D. Dubourdieu, B. Doneche, A. Lonvaud, Y. Glories, A. Maujean, J.M. Branco, Handbook of Enology, The Microbiology of Wine and Vinifications, J. Wiley \& Sons, West Sussex, England, 2006.

[9] A. Ortega-Regules, I. Romero-Cascales, J.M. Ros-García, J.M. López-Roca, E. Gómez-Plaza, A first approach towards the relationship between grape skin cell-wall composition and anthocyanin extractability, Anal. Chim. Acta 563(1-2) (2006) 26-32. 
[10] A. Ortega-Regules, J.M. Ros-García, A.B. Bautista-Ortín, J.M. López-Roca, E. Gómez-Plaza, Changes in skin cell wall composition during the maturation of four premium wine grape varieties, J. Sci. Food Agric. 88(3) (2008) 420-428.

[11] J. Hidalgo Togores, Tratado de enología: tomo I (2a. ed.), Mundi-Prensa, Madrid, España, 2010.

[12] M. Pinelo, A. Arnous, A.S. Meyer, Upgrading of grape skins: Significance of plant cell-wall structural components and extraction techniques for phenol release, Trends Food Sci Tech 17(11) (2006) 579-590.

[13] C. Asselin, D. Delteil, Vinificaciones: principales operaciones unitarias comunes, Enología: fundamentos científicos y tecnológicos, AMV Ediciones y Mundi-Prensa, Madrid, España, 2003, pp. 418-442.

[14] B. Kemps, L. Leon, S. Best, J. De Baerdemaeker, B. De Ketelaere, Assessment of the quality parameters in grapes using VIS/NIR spectroscopy, Biosyst. Eng. 105(4) (2010) 507-513.

[15] F.J. Rodríguez-Pulido, J.M. Hernández-Hierro, J. Nogales-Bueno, B. Gordillo, M.L. González-Miret, F.J. Heredia, A novel method for evaluating flavanols in grape seeds by near infrared hyperspectral imaging, Talanta 122(0) (2014) 145-150.

[16] J. Nogales-Bueno, B. Baca-Bocanegra, F.J. Rodríguez-Pulido, F.J. Heredia, J.M. Hernández-Hierro, Use of near infrared hyperspectral tools for the screening of extractable polyphenols in red grape skins, Food Chem. 172 (2015) 559-564.

[17] F. Torchio, S. Río Segade, S. Giacosa, V. Gerbi, L. Rolle, Effect of Growing Zone and Vintage on the Prediction of Extractable Flavanols in Winegrape Seeds by a FTNIR Method, J. Agric. Food. Chem. 61(38) (2013) 9076-9088. 
[18] R. Ferrer-Gallego, J.M. Hernández-Hierro, J.C. Rivas-Gonzalo, M.T. EscribanoBailón, Determination of phenolic compounds of grape skins during ripening by NIR spectroscopy, Lwt-Food Sci Technol 44(4) (2011) 847-853.

[19] J. Nogales-Bueno, J.M. Hernández-Hierro, F.J. Rodríguez-Pulido, F.J. Heredia, Determination of technological maturity of grapes and total phenolic compounds of grape skins in red and white cultivars during ripening by near infrared hyperspectral image: A preliminary approach, Food Chem. 152 (2014) 586-591.

[20] L. Bokobza, Near infrared spectroscopy, J. Near Infrared Spectrosc. 6(1) (1998) 317.

[21] A. Femenia, E.S. Sánchez, S. Simal, C. Rosselló, Effects of Drying Pretreatments on the Cell Wall Composition of Grape Tissues, J. Agric. Food. Chem. 46(1) (1998) 271-276.

[22] H.J. Byrne, M.K. Ostrowska, H. Nawaz, J. Dorney, D.A. Meade, F. Bonnier, M.F. Lyng, Vibrational Spectroscopy: Disease Diagnostics and Beyond, in: M. Baranska (Ed.), Optical Spectroscopy and Computational Methods in Biology and Medicine, Springer Netherlands, Dordrecht, Netherlands, 2014, pp. 355-399.

[23] H.J. Byrne, G.D. Sockalingum, N. Stone, Chapter 4 Raman Microscopy: Complement or Competitor?, Biomedical Applications of Synchrotron Infrared Microspectroscopy: A Practical Approach, The Royal Society of Chemistry, Karlsruhe, Germany, 2011, pp. 105-143.

[24] A.J.J. Zietsman, J.P. Moore, J.U. Fangel, W.G.T. Willats, J. Trygg, M.A. Vivier, Following the Compositional Changes of Fresh Grape Skin Cell Walls during the Fermentation Process in the Presence and Absence of Maceration Enzymes, J. Agric. Food. Chem. 63(10) (2015) 2798-2810. 
[25] J.L. Acebes, A. Largo-Gosens, M. Hernández-Altamirano, L. García-Calvo, A. Alonso-Simón, J.M. Álvarez, Fourier Transform Mid InfraRed spectroscopy applications for monitoring the structural plasticity of plant cell walls, Front Plant Sci. 5 (2014).

[26] M. Fasoli, R. Dell'Anna, S. Dal Santo, R. Balestrini, A. Sanson, M. Pezzotti, F. Monti, S. Zenoni, Pectins, Hemicelluloses and Celluloses Show Specific Dynamics in the Internal and External Surfaces of Grape Berry Skin During Ripening, Plant Cell Physiol. 57(6) (2016) 1332-1349.

[27] C. Kyomugasho, S. Christiaens, A. Shpigelman, A.M. Van Loey, M.E. Hendrickx, FT-IR spectroscopy, a reliable method for routine analysis of the degree of methylesterification of pectin in different fruit- and vegetable-based matrices, Food Chem. 176 (2015) 82-90.

[28] M. Szymańska-Chargot, M. Chylińska, P.M. Pieczywek, P. Rösch, M. Schmitt, J. Popp, A. Zdunek, Raman imaging of changes in the polysaccharides distribution in the cell wall during apple fruit development and senescence, Planta 243(4) (2016) 935-945. [29] N. Gierlinger, T. Keplinger, M. Harrington, Imaging of plant cell walls by confocal Raman microscopy, Nat. Protocols 7(9) (2012) 1694-1708.

[30] C.E. da Silva, P. Vandenabeele, H.G.M. Edwards, L.F. Cappa de Oliveira, NIRFT-Raman spectroscopic analytical characterization of the fruits, seeds, and phytotherapeutic oils from rosehips, Anal. Bioanal. Chem. 392(7) (2008) 1489-1496.

[31] M. Chylińska, M. Szymańska-Chargot, A. Zdunek, Imaging of polysaccharides in the tomato cell wall with Raman microspectroscopy, Plant Methods 10(1) (2014) 1-9.

[32] J.S. Shenk, M.O. Westerhaus, Population Definition, Sample Selection, and Calibration Procedures for Near Infrared Reflectance Spectroscopy, Crop Sci. 31 (1991) $469-474$. 
[33] K. Flores, M.-T. Sánchez, D. Pérez-Marín, J.-E. Guerrero, A. Garrido-Varo, Feasibility in NIRS instruments for predicting internal quality in intact tomato, J. Food Eng. 91(2) (2009) 311-318.

[34] V.L. Singleton, J.A. Rossi, Colorimetry of Total Phenolics with PhosphomolybdicPhosphotungstic Acid Reagents, Am. J. Enol. Vitic. (16) (1965) 144-158.

[35] N. Vivas, Y. Glories, L. Lagune, C. Saucier, M. Augustin, Estimation du degré de polymérisation des procyanidines du raisin et du vin par la méthode au pdimethylaminocinnamaldéhyde, J Int Sci Vigne Vin. 28 (1994) 319-336.

[36] M. García-Marino, J.M. Hernández-Hierro, J.C. Rivas-Gonzalo, M.T. EscribanoBailón, Colour and pigment composition of red wines obtained from co-maceration of Tempranillo and Graciano varieties, Anal. Chim. Acta 660(1-2) (2010) 134-142.

[37] J.M. Hernández-Hierro, J. Nogales-Bueno, F.J. Rodríguez-Pulido, F.J. Heredia, Feasibility study on the use of near-infrared hyperspectral imaging for the screening of anthocyanins in intact grapes during ripening, J. Agric. Food. Chem. 61(41) (2013) 9804-9809.

[38] V. Mazet, C. Carteret, D. Brie, J. Idier, B. Humbert, Background removal from spectra by designing and minimising a non-quadratic cost function, Chemometrics Intellig. Lab. Syst. 76(2) (2005) 121-133.

[39] R. Bro, A.K. Smilde, Principal component analysis, Analytical Methods 6(9) (2014) 2812-2831.

[40] F. Bonnier, H.J. Byrne, Understanding the molecular information contained in principal component analysis of vibrational spectra of biological systems, The Analyst 137(2) (2012) 322-32. 
[41] P. Rajkumar, N. Wang, G. Eimasry, G.S.V. Raghavan, Y. Gariepy, Studies on banana fruit quality and maturity stages using hyperspectral imaging, J. Food Eng. 108(1) (2012) 194-200.

[42] R.H. Wilson, A.C. Smith, M. Kačuráková, P.K. Saunders, N. Wellner, K.W. Waldron, The Mechanical Properties and Molecular Dynamics of Plant Cell Wall Polysaccharides Studied by Fourier-Transform Infrared Spectroscopy, Plant Physiol. 124(1) (2000) 397-406.

[43] M. Szymanska-Chargot, A. Zdunek, Use of FT-IR Spectra and PCA to the Bulk Characterization of Cell Wall Residues of Fruits and Vegetables Along a Fraction Process, Food Biophys 8(1) (2013) 29-42.

[44] J.A. Heredia-Guerrero, J.J. Benítez, E. Domínguez, I. Bayer, R. Cingolani, A. Athanassiou, A. Heredia, Infrared and Raman spectroscopic features of plant cuticles: a review, Front Plant Sci. 5 (2014).

[45] Y. Gao, J.U. Fangel, W.G.T. Willats, M.A. Vivier, J.P. Moore, Dissecting the polysaccharide-rich grape cell wall changes during winemaking using combined highthroughput and fractionation methods, Carbohydr. Polym. 133 (2015) 567-577.

[46] R.L. Hanlin, M. Hrmova, J.F. Harbertson, M.O. Downey, Review: Condensed tannin and grape cell wall interactions and their impact on tannin extractability into wine, Aust. J Grape Wine R. 16(1) (2010) 173-188.

[47] H.W. Siesler, Y. Ozaky, S. Kawata, H.M. Heise, Near infrared spectroscopy: principles, instruments, applications, Wiley-VCH, Weinheim, Germany, 2002.

[48] F. Bonnier, A. Mehmood, P. Knief, A.D. Meade, W. Hornebeck, H. Lambkin, K. Flynn, V. McDonagh, C. Healy, T.C. Lee, F.M. Lyng, H.J. Byrne, In vitro analysis of immersed human tissues by Raman microspectroscopy, J Raman Spectrosc. 42(5) (2011) 888-896. 
[49] N. Gierlinger, M. Schwanninger, Chemical Imaging of Poplar Wood Cell Walls by Confocal Raman Microscopy, Plant Physiol. 140(4) (2006) 1246-1254.

[50] J.S. Lupoi, E. Gjersing, M.F. Davis, Evaluating Lignocellulosic Biomass, Its Derivatives, and Downstream Products with Raman Spectroscopy, Front Bioeng Biotechnol. 3(50) (2015).

[51] K. Seidler-Lozykowska, M. Baranska, R. Baranski, D. Krol, Raman analysis of caraway (Carum carvi L.) single fruits. Evaluation of essential oil content and its composition, J. Agric. Food. Chem. 58(9) (2010) 5271-5. 


\section{Figure captions}

Figure 1: (A) Average and standard deviation of raw ATR-FTIR spectra for the external and internal surfaces of grape skin NEM samples. (B) Score plot of the first two principal components after PCA performed on ATR-FTIR spectra recorded from grape skin NEM samples. The individual data points have been codified as external and internal surfaces of grape skin NEM samples. (C) PC1 and PC2 loading plot. (D) Comparison between pre-treated ATR-FTIR spectra and PC1 loading plot for grape skin NEM samples.

Figure 2: (A) Raw Raman spectrum, baseline and corrected spectrum for a grape skin NEM sample. (B) Score plot of the first two principal components after PCA performed on Raman spectra recorded from grape skin NEM samples. The individual data points have been codified as external and internal surface. 
Table 1. Extractability levels of total phenols, flavanols and anthocyanins for grape skin samples, expressed as percentage. Means and standard deviations are shown. For each phenolic family, different letters in the same column indicate statistical differences (Tukey test, $\alpha=0.05$ ).

\begin{tabular}{cccccccc}
\hline & & \multicolumn{5}{c}{ Extractabilities (expressed as percentage) } \\
\cline { 3 - 8 } Samples & $\mathrm{n}$ & \multicolumn{2}{c}{ Total phenols } & \multicolumn{2}{c}{ Flavanols } & \multicolumn{2}{c}{ Anthocyanins } \\
\cline { 3 - 8 } & & Mean & SD & Mean & SD & Mean & SD \\
\hline All & 34 & 56.35 & 8.66 & 35.16 & 9.60 & 87.36 & 8.08 \\
\hline Low & 4 & $39.79^{\mathrm{a}}$ & 9.28 & $19.32^{\mathrm{a}}$ & 2.53 & $80.80^{\mathrm{a}}$ & 6.81 \\
Medium & 15 & $54.83^{\mathrm{b}}$ & 4.16 & $31.14^{\mathrm{b}}$ & 5.69 & $84.29^{\mathrm{a}}$ & 8.70 \\
High & 15 & $62.29^{\mathrm{c}}$ & 4.72 & $43.45^{\mathrm{c}}$ & 4.56 & $92.17^{\mathrm{b}}$ & 4.72 \\
\hline
\end{tabular}

n: number of samples; 
Table 2. Main functional groups assigned to the different vibrations present in the ATR-FTIR spectra of non-extracted material (NEM) from grape skin samples.

\begin{tabular}{|c|c|c|c|c|}
\hline \multirow{2}{*}{ Assignment $^{a}$} & \multicolumn{2}{|c|}{$\begin{array}{c}\text { Absorption bands }\left(\mathrm{cm}^{-1}\right) \\
\left(\text { Intensity }{ }^{b}\right)\end{array}$} & \multirow{2}{*}{ Component } & \multirow{2}{*}{ References } \\
\hline & $\begin{array}{l}\text { External } \\
\text { surface }\end{array}$ & $\begin{array}{c}\text { Internal } \\
\text { surface }\end{array}$ & & \\
\hline$v(\mathrm{O}-\mathrm{H})$ & $3322(w, b)$ & $3324(\mathrm{~m}, \mathrm{~b})$ & Polysaccharides, cutin & [44] \\
\hline$v_{\mathrm{a}}\left(\mathrm{CH}_{2}\right)$ & 2916 (vs) & $2916(\mathrm{~m})$ & Waxes, cutin, lipids & $[26,44])$ \\
\hline$v_{\mathrm{s}}\left(\mathrm{CH}_{2}\right)$ & 2850 (vs) & $2850(w)$ & Waxes, cutin, lipids & {$[26,44]$} \\
\hline$v(\mathrm{C}=\mathrm{O})_{\mathrm{ester}}$ & $1732(\mathrm{~m})$ & $1732(w)$ & $\begin{array}{l}\text { Polyesters, pectins, } \\
\text { cutin }\end{array}$ & {$[26,42-44]$} \\
\hline$v_{\mathrm{a}}\left(\mathrm{COO}^{-}\right)$ & $1620(w)$ & $1612(\mathrm{~m})$ & Pectins & {$[26,42-44]$} \\
\hline$v(\mathrm{C}-\mathrm{C})_{\text {aromatic }}$ & $1517(w)$ & $1519(w)$ & Phenolics & [44] \\
\hline$\delta\left(\mathrm{CH}_{2}\right)_{\text {scissoring }}$ & $1464(\mathrm{~m})$ & & Waxes, cutin, lipids & {$[42,44]$} \\
\hline$v(\mathrm{C}-\mathrm{C})_{\text {aromatic }}$ & & $1440(w)$ & Phenolics & [44] \\
\hline $\begin{array}{c}v_{\mathrm{a}}(\mathrm{C}-\mathrm{O}- \\
\mathrm{C})_{\text {glycosidic }}\end{array}$ & $1167(w)$ & & $\begin{array}{l}\text { Polysaccharides, } \\
\text { pectins, cutin }\end{array}$ & {$[26,42-44]$} \\
\hline $\begin{array}{c}v(\mathrm{C}-\mathrm{O}) \text { and } \\
v(\mathrm{C}-\mathrm{C})\end{array}$ & $1013(\mathrm{~m})$ & $1018(\mathrm{~s})$ & $\begin{array}{c}\text { Polysaccharides, } \\
\text { pectins }\end{array}$ & {$[26,42,43]$} \\
\hline$\delta\left(\mathrm{CH}_{2}\right)_{\text {rocking }}$ & $720(\mathrm{~m})$ & & Waxes, cutin & {$[26,44]$} \\
\hline
\end{tabular}

${ }^{\alpha}$ Assignment: $v$, stretching; $\delta$, bending; s, symmetric; a, asymmetric.

${ }^{b}$ Intensity: w, weak; m, medium; s, strong; vs, very strong; b, broad. 
Table 3. Main functional groups assigned to the different vibrations present in the Raman spectra of non-extracted material (NEM) from grape skin samples.

\begin{tabular}{|c|c|c|c|}
\hline Assignment $^{a}$ & $\begin{array}{c}\text { Raman shifts }\left(\mathrm{cm}^{-1}\right) \\
(\text { Intensity } \\
\left.{ }^{b}\right)\end{array}$ & Component & Reference \\
\hline$v\left(\mathrm{CH}_{2}\right)$ & $2902(\mathrm{vw}, \mathrm{b})$ & Polysaccharides, cutin & $\begin{array}{l}{[28,31} \\
50]\end{array}$ \\
\hline$v(\mathrm{C}=\mathrm{C})_{\text {aromatic }}$ & $1606(\mathrm{~m})$ & Lignins, phenolics & {$[30,51]$} \\
\hline$\delta\left(\mathrm{CH}_{2}\right)_{\text {scissoring }}$ & $1442(w)$ & Lignins, lipids, cutin & $\begin{array}{c}{[30,49,} \\
51]\end{array}$ \\
\hline $\begin{array}{c}\delta(\mathrm{HCC}), \delta(\mathrm{HCO}) \\
\delta(\mathrm{HOC})\end{array}$ & $1342(\mathrm{~s})$ & Polysaccharides & $\begin{array}{c}{[28,49,} \\
50]\end{array}$ \\
\hline$\delta\left(\mathrm{CH}_{2}\right)_{\text {twisting }}$ & $1295(\mathrm{~s})$ & $\begin{array}{l}\text { Lignins, fatty acids, } \\
\text { polysaccharides, cutin }\end{array}$ & $\begin{array}{l}{[30,49,} \\
50]\end{array}$ \\
\hline $\begin{array}{c}v(\mathrm{C}-\mathrm{C}), v(\mathrm{C}-\mathrm{O}), \\
v_{\mathrm{s}}(\mathrm{C}-\mathrm{O}-\mathrm{C})_{\text {glycosidic }}\end{array}$ & $1123(w)$ & Polysaccharides & $\begin{array}{c}{[30,31} \\
50]\end{array}$ \\
\hline
\end{tabular}

${ }^{\alpha}$ Assignment: $v$, stretching; $\delta$, bending; s, symmetric.

${ }^{b}$ Intensity: vw, very weak; w, weak; m, medium; s, strong; b, broad. 

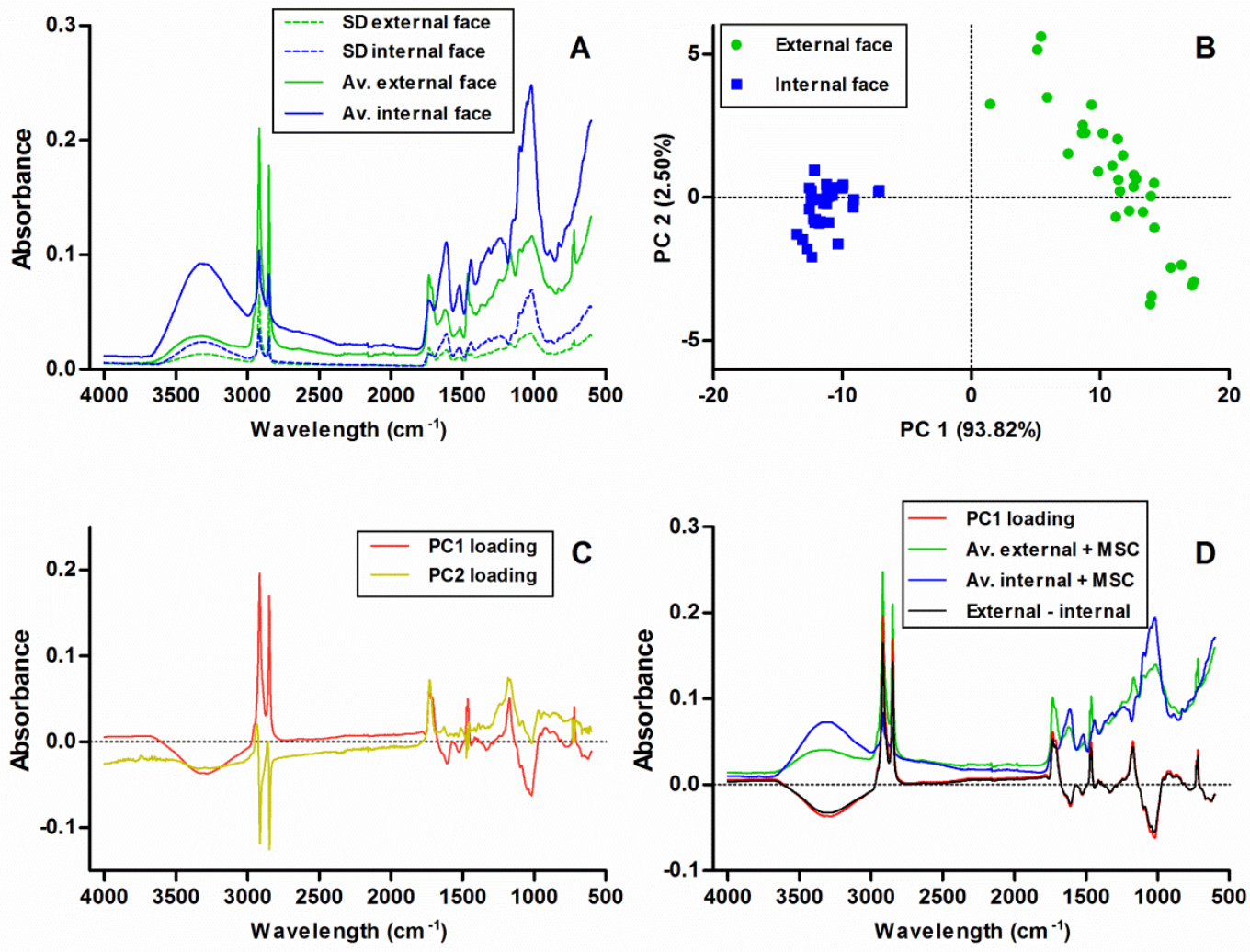

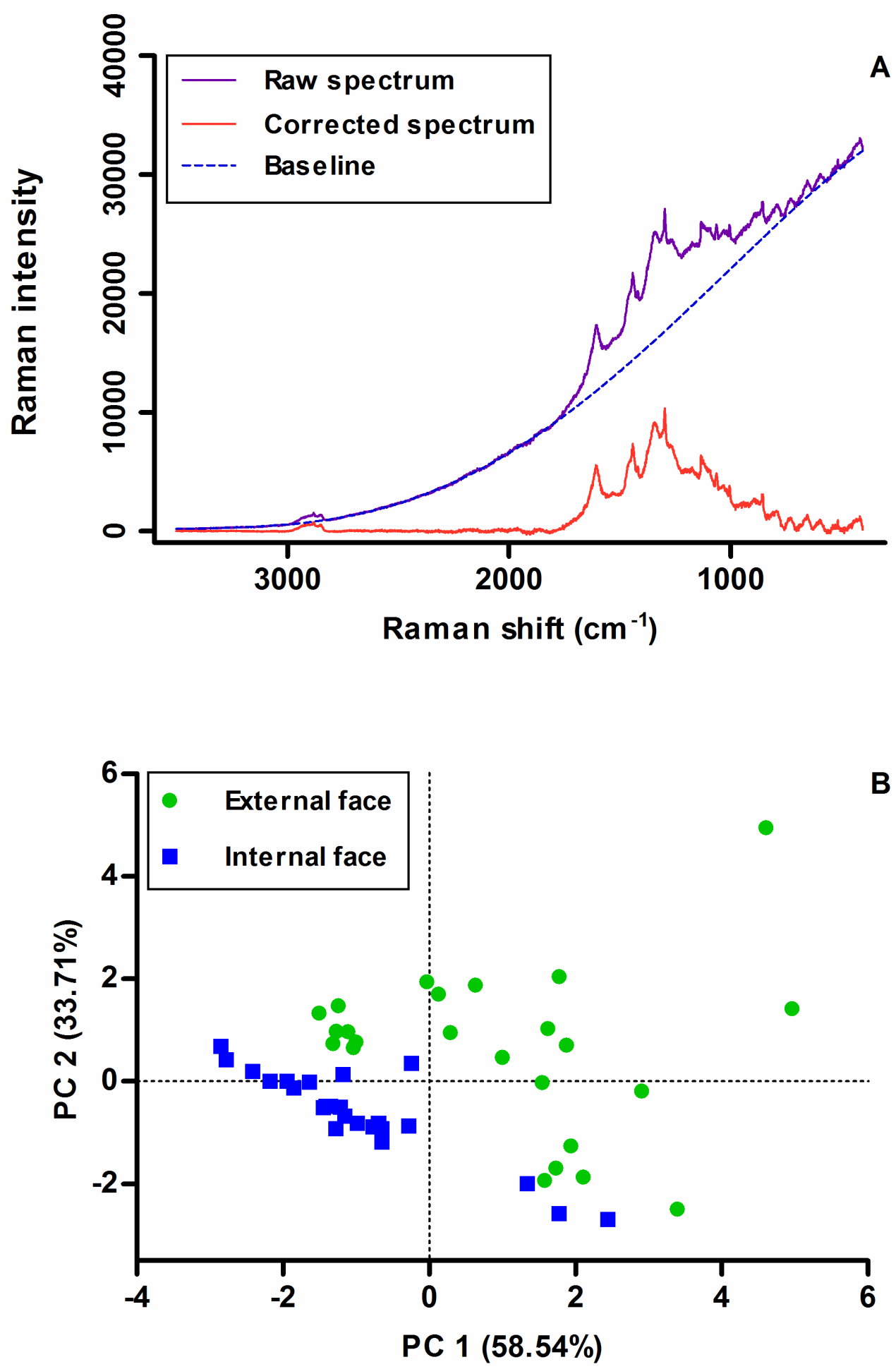